Bull. Mater. Sci., Vol. 17, No. 6, November 1994, pp. 1155-1166. (C Printed in India.

\title{
New galvanic cell designs for minimizing electrode polarization
}

\author{
K T JACOB* and SUKANYA MUKHOPADHYAY \\ Department of Metallurgy and *Materials Research Centrc, Indian Institute of Science, \\ Bangalore 560 012, India
}

\begin{abstract}
Ahstract. New galvanic cell designs, incorporating one or two buffer electrodes, are developed to minimize the electrode polarization caused by electrochemical permeability of the electrolyte at high temperature. When a nonpolarizable reference electrode is empioyed, a cell with three-electrode compartments can be used to measure the chemical potential of oxygen in two-phase fields of ternary systems, associated with one degree of freedom at constant temperature. A buffer electrode is placed between the reference and measuring electrodes. The buffer electrode, maintained at approximately the same oxygen chemical potential as the measuring electrode, absorbs the semipermeability flux of oxygen between reference and measuring electrodes.

When the reference electrode is polarizable, two buffer electrodes are required between the reference and measuring electrodes. The reference and reference-buffer electrodes have the same chemical potential of the active species. Similarly the measuring electrode and its buffer are of approximately the same chemical potential. A significant chemical potential difference exists only between the two buffers, which may become polarized due to coupled transport of ions and electronic defects through the electrolyte. Since the reference and measuring electrodes are insulated, the emf of the solid state cell is unaffected. The use of the buffer electrode designs permit more accurate thermodynamic measurements on metal and ceramic systems at high temperature.
\end{abstract}

Keywords. Electrode polarization; semipermeability flux; buffer electrode; solid electrolyte cells.

\section{Introduction}

Solid state galvanic cells have been extensively used for high temperature thermodynamic studies on materials (Pratt 1990). An important factor which is often responsible for incorrect measurement of chemical potential when using a solid state galvanic cell is electrode polarization. Polarization occurs as a result of physical or electrochemical permeability of the solid electrolyte. While physical permeability can be reduced by using a dense form of the solid electrolyte, free from interconnecting porosity, electrochemical permeability results from the intrinsic properties of the material. When the difference in the chemical potential of active species such as oxygen between the measuring and reference electrodes is substantial, there is always a small flux of this species through the electrolyte separating them, even in the absence of physical porosity (Fouletier et al 1976). The electrochemical permeability is caused by the coupled transport of oxygen ions and electrons or holes in an oxide solid electrolyte under the oxygen potential gradient. This flow of oxygen can be stopped only by opposing it with an external d.c. voltage, equivalent to the oxygen chemical potential difference (Jacob and Jeffes 1971). Unless the electrochemical reactions at the electrodes are sufficiently rapid, the flux of oxygen can lead to polarization of the electrodes. In this article new designs of galvanic cells are suggested that minimize the effect of polarization. The new 
designs permit extremely accurate thermodynamic measurements at high temperature, unparalleled by any other technique currently available.

When gas electrodes are used, the presence of polarization manifests as flow rate dependence of emf. Although polarization can be reduced by increasing the flow rate, a practical limit is set by the cooling effect of the streaming gas. Asymmetrical gas flows at the two electrodes can result in differential cooling and non-isothermal contributions to cell emf which are difficult to correct.

There have been few earlier attempts to minimize polarization in high temperature galvanic sensors. The idea of deflecting the electrochemical flux of oxygen by a zirconia point electrode configuration was suggested by Fouletier et al (1976). The design of the point electrode is illustrated in figure 1 . The platinum lead electrode actually measures the chemical potential in a 'microsystem' formed at the triple phase region between the electrode, electrolyte and gas. The oxygen flux through the electrolyte due to electrochemical semipermeability may alter the equilibrium oxygen chemical potential in the microsystem, if the exchange kinetics between the gas phase and the microsystem does not keep pace with the semipermeability flux. The point electrode deflects the oxygen flux away from the 'microsystem' at the triple phase contact. Since the ionic flux takes the lowest resistance path, this flux is dissipated at the tip of the point electrode made using the same material as the electrolyte. The measured composition of the gas at the platinum lead is unaffected and corresponds to that of the bulk gas. Jacob et al (1982) have shown that the performance of the point electrode can be improved by applying a porous coating of a catalyst such as $\mathrm{Pt}$ at the tip of the point electrode made from the solid electrolyte material. The catalyst helps to dissipate the flux faster at the tip.

Mallika et al (1986) proposed a design in which a solid electrolyte, a buffer electrode and a point electrolyte are interposed between the reference and test electrodes, as shown in figure 2 . The buffer electrode absorbs the flux arriving from the reference electrodes. However, the buffer electrode has an oxygen chemical potential intermediate between the reference and the test electrodes. The buffer and the test electrodes are separated by a point electrode. made of an ionic conductor.

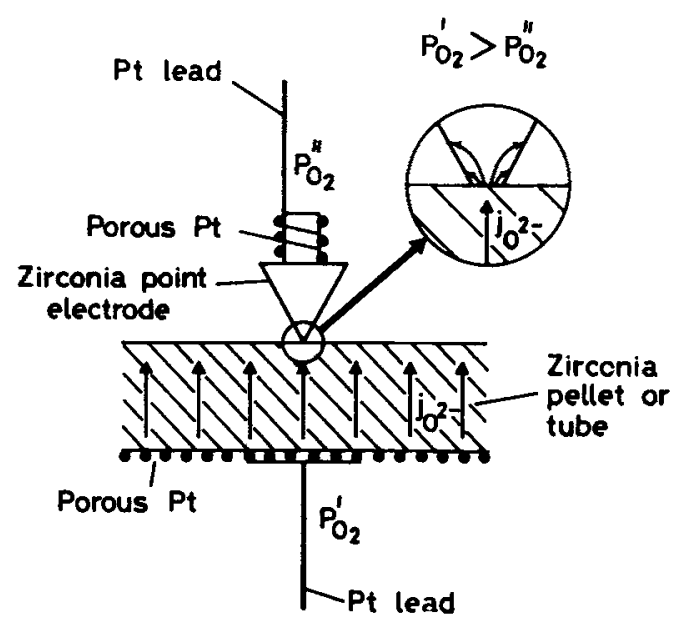

Figure 1. A schematic representation of the point electrode for deflecting the semipermeability flux from the measuring electrode (after Fouletier et al 1976). 


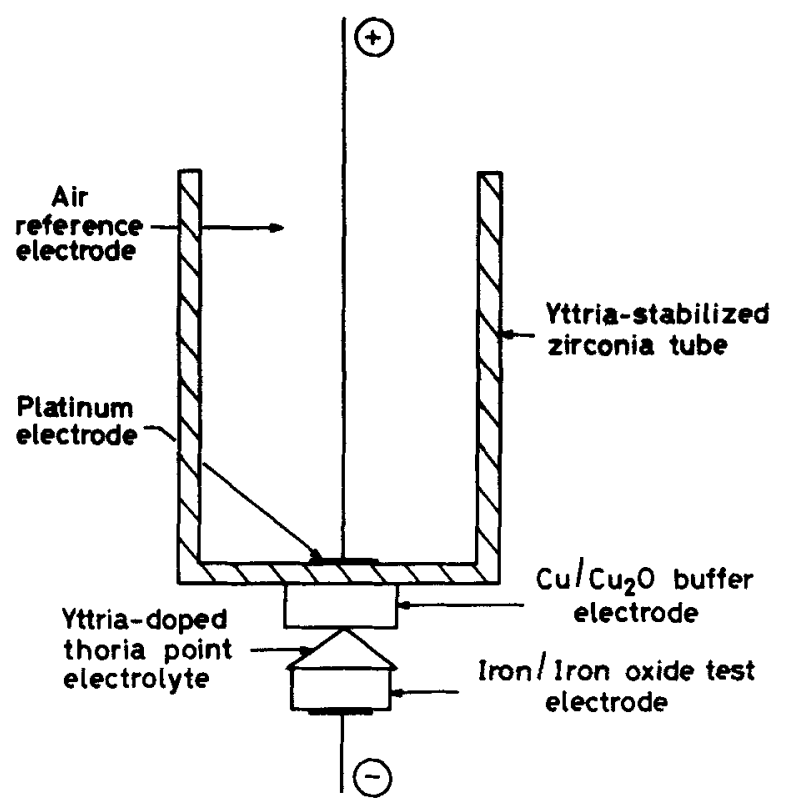

Figure 2. Schematic of triple electrode-bielectrolyte cell arrangement (after Mallika et al 1986).

In this design, the point electrode does not deflect the flux. However, it reduces the contact area between the buffer and the solid electrolyte, and reduces the flux between the buffer and test electrode. The major disadvantage of their design is that both the buffer and the measuring electrodes are exposed to a common gas phase. The transfer of oxygen between the electrodes via the gas, mediated by the presence of the trace concentrations of $\mathrm{H}_{2} \mathrm{O}, \mathrm{CO}$ and $\mathrm{CO}_{2}$ in the inert gas blanket, can significantly affect the emf.

Lundberg and Rosén (1992) proposed another design of a galvanic cell, shown in figure 3, with a gas buffer electrode maintained at the same chemical potential of the measuring electrode. They used two solid electrolyte tubes, one containing the solid reference electrode, and the other containing the condensed phase test electrode. Pt leads connected to the outside of each solid electrolyte tube were joined. The oxygen partial pressure in the inert gas phase between the two solid electrolyte tubes was maintained at the same value as that in the measuring electrode. This was achieved by placing a large amount of the measuring electrode mixture in the proximity of the solid electrolyte tubes, but without physical contact. The design avoids the polarization of the measuring electrode, but does not necessarily prevent the polarization of the reference electrode. To overcome the drawbacks of the earlier arrangements, new designs are proposed and their efficacy tested.

\section{Design of a galvanic cell with three compartments}

\subsection{Principle}

When a nonpolarizable reference electrode is employed, a cell design with three 


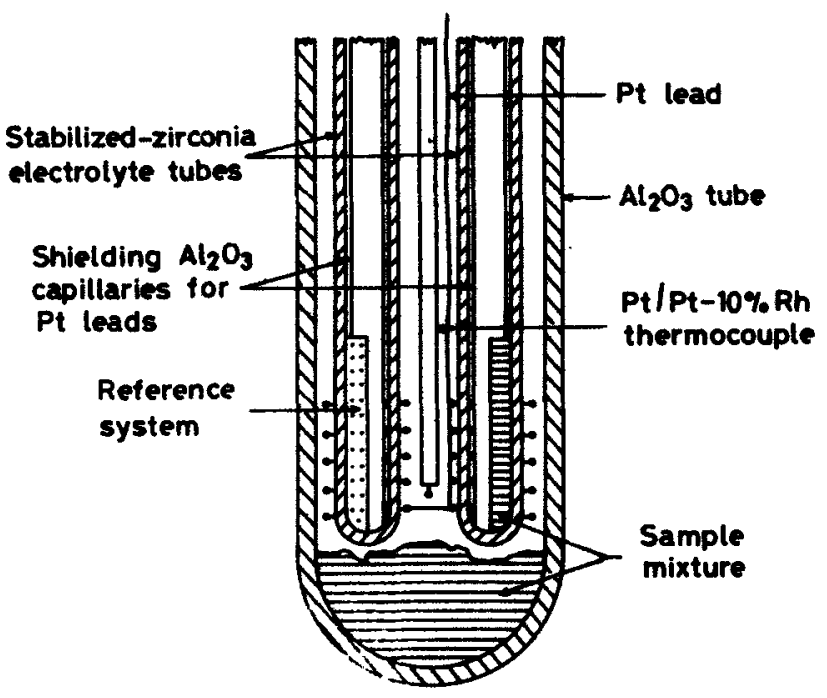

Figure 3. Design of a galvanic cell with a gas buffer electrode (after Lundberg and Rosen 1992).

electrode compartments can be used to avoid polarization of the measuring electrode. A buffer electrode, identical to the measuring electrode, is placed between the reference and the measuring electrodes. Thus there is no flux between the buffer and the measuring electrode as their chemical potentials are the same. The buffer essentially insulates measuring electrode from polarization. Since the reference electrode is nonpolarizable, and.the measuring electrode is protected from polarization, the cell emf is unaffected by the electrochemical flux of oxygen through the intervening solid electrolyte. Pure oxygen, at a fixed pressure, constitutes a nonpolarizable electrode. It also serves as a primary standard for oxygen potential. Other multiphase electrodes, associated with high exchange currents or fast reaction rates, may also function as nonpolarizable electrodes under narrowly specified conditions.

If an electrode is composed of a chemically invariant system at constant temperature and pressure, and the electrode reactions are sufficiently rapid, the semipermeability flux of oxygen does not generally alter its chemical potential. Experimentally, the effect of semipermeability flux on emf can be minimized by taking a greater amount of the phase that is consumed by the flux at each of the solid electrodes (Jacob and Mathews 1990). Electrochemical techniques for the measurement of oxygen potential of an invariant system at constant temperature are reasonably well established (Pratt 1990). However, measurements on systems that have one or more degrees of freedom are more difficult, especially if the phases involved are solids. The composition of the solid at the electrode-electrolyte interface may be altered by minor perturbations such as oxygen leakage, physical or electrochemical.

A system with one degree of freedom at experimental temperatures was encountered in the study of the ternary Mn-Rh-O (Jacob and Sriram 1994). Phase diagram for the system is shown in figure 4 . Metallic $R h$ coexists with the spinel solid solution $\mathrm{Mn}_{3.2 x} \mathrm{Rh}_{2 x} \mathrm{O}_{4}$. This two-phase equilibrium in the ternary system is associated with ne degree of freedom. The equilibrium partial pressure of oxygen can vary with 


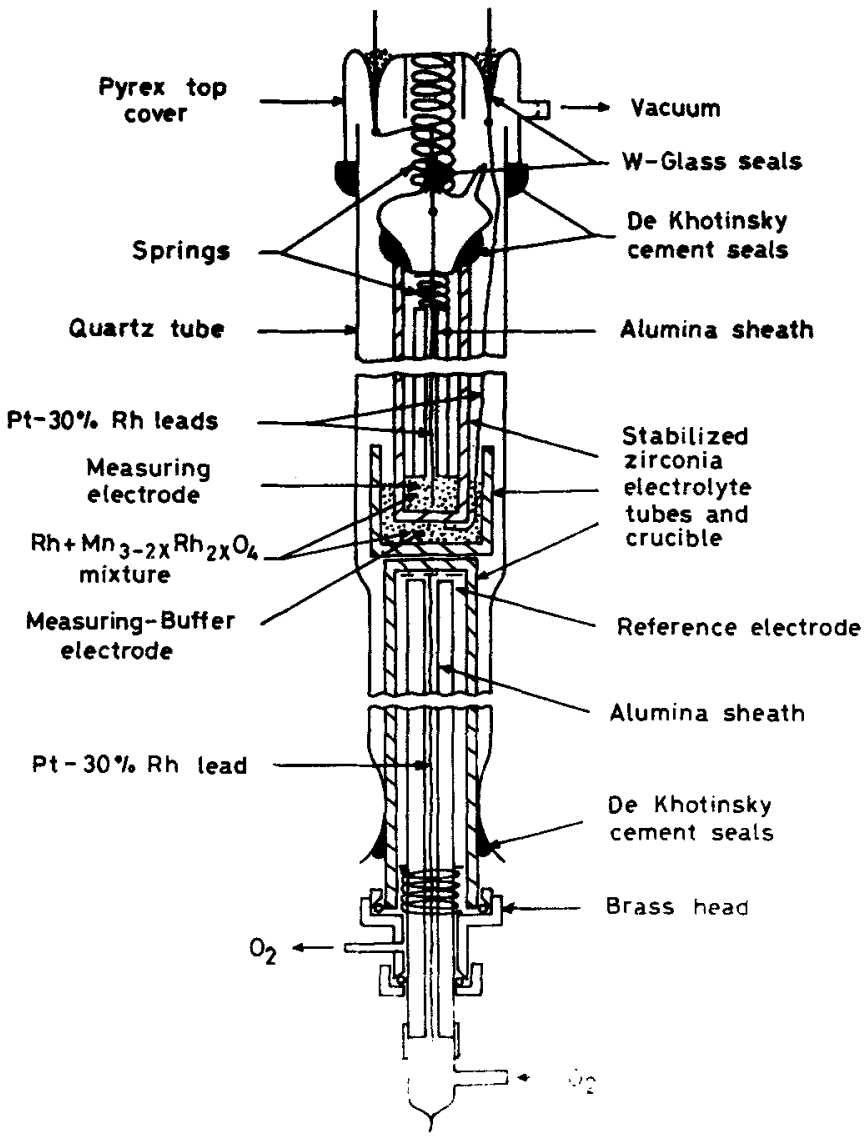

Figure 4. Schematic diagram of the three-electrode system (cell 1 , for emf measurement.

the composition of the spinel solid solution at constant temperature. To measure the thermodynamic mixing properties of the solid solution, it is necessary to determine the composition dependence of the partial pressure in the two-phase region.

Initial measurements on two-phase equilibria using the conventional two-compartment arrangement (Kale and Jacob 1992) with physical separation of the two electrodes by a long solid electrolyte tube, were not successful. The emf was found to drift gradually with time. The drift was reduced, when a sealed system, suggested by Charette and Flengas (1968), was employed. The interaction with the gas phase was minimized in a closed system. However, the drift could not be suppressed completely. The electrochemical flux of oxygen through the electrolyte was found to change the composition of the spinel solid solution at the electrode/electrolyte interphase.

To make accurate measurements, a cell design shown in figure 5 was used (Jacob and Sriram 1994). It consisted of three distinct compartments, separated by two physically impervious yttria-stabilized zirconia tubes, each closed at one end. The cell can be represented as: 


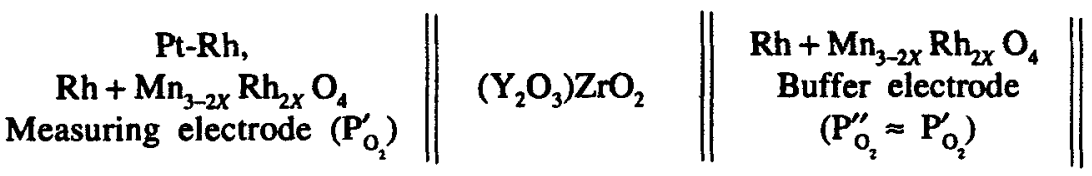

$$
\begin{aligned}
& \left\|\left(\mathrm{Y}_{2} \mathrm{O}_{3}\right) \mathrm{ZrO}_{2}\right\| \begin{array}{c}
\mathrm{O}_{2}, \mathrm{Pt}-\mathrm{Rh} \\
\text { Reference electrode } \\
\left(\mathrm{P}_{\mathrm{O}_{2}}=1.01 \times 10^{5} \mathrm{~Pa}\right)
\end{array}
\end{aligned}
$$

The measuring and reference electrodes were contained inside two separate zirconia tubes. The measuring electrode consisted of an intimate mixture of $\mathrm{Rh}$ and $\mathrm{Mn}_{3-2 \mathrm{X}} \mathrm{Rh}_{2 \mathrm{X}} \mathrm{O}_{4}$ powders in equimolar ratio. The mixture was rammed against the closed end of a stabilized-zirconia tube with a Pt-30\% Rh lead embedded in the mixture. An alumina sheath was used to insulate this lead and to press the measuring electrode against the zirconia tube. The top of the zirconia tube was sealed with De Khotinsky cement to a bell-shaped pyrex tube, which supported a W electrode connection sealed into the glass. The assembled measuring electrode half-cell was first evacuated using a side arm tube, heated to $\sim 400 \mathrm{~K}$, and then the tube was flame-sealed under vacuum.

The measuring half-cell assembly rested on a buffer electrode contained in a stabilized-zirconia crucible. The buffer also consisted of a mixture of $\mathbf{R h}$ and $\mathrm{Mn}_{3-2 x} \mathrm{Rh}_{2 x} \mathrm{O}_{4}$, but the spinel phase was slightly richer in $\mathrm{Mn}_{3} \mathrm{O}_{4}$ than in the measuring electrode. Thus the partial pressure of oxygen in the buffer was slightly less $(\sim 15 \mathrm{mV})$ than that of the measuring electrode. The buffer electrode was prepared by consolidating an intimate equimolar mixture of constituent phases in the zirconia crucible, with a Pt-30\% $\mathrm{Rh}$ lead embedded in the powder.

The zirconia crucible rested on another inverted zirconia tube, through which pure oxygen gas was passed at a pressure of $1.01 \times 10^{5} \mathrm{~Pa}$ and a flow rate of $3 \mathrm{ml}$ $\mathrm{s}^{-1}$. The pressure inside the tube was controlled by a cascade of bubblers placed at the gas exit. The oxygen electrode served as the reference. The mating surfaces of the crucible and the tube were polished with diamond paste to minimize contact resistance. The inside surface of the inverted tube was platinized. A Pt gauze was pressed against the closed end of the inverted tube using an alumina sheath. A Pt-30\% Rh lead, spot-welded to the gauze, was passed through the alumina sheath. The open end of the tube was fitted with a brass-head.

The cell was then assembled inside a fused quartz enclosure as shown in figure 5. All electrode connections were silver soldered. The outer quartz enclosure was also evacuated from a side arm tube and flame-sealed under vacuum. The top half of the cell assembly shown in figure 5, was identical to that developed by Charette and Flengas (1968). The entire assembly was placed inside a vertical resistance furnace, with the electrodes located in the even-temperature zone $( \pm 1 \mathrm{~K})$. The upper and the lower parts of the assembly, where cement seals were located, remained at room temperature during measurement. A Faraday cage made from stainless steel foil was placed between the furnace and the cell assembly. The foil was grounded to minimize induced emf on cell-leads. The temperature of the furnace was controlled to $\pm 1 \mathrm{~K}$. The cell potentials were measured with a high impedance digital voltmeter. 


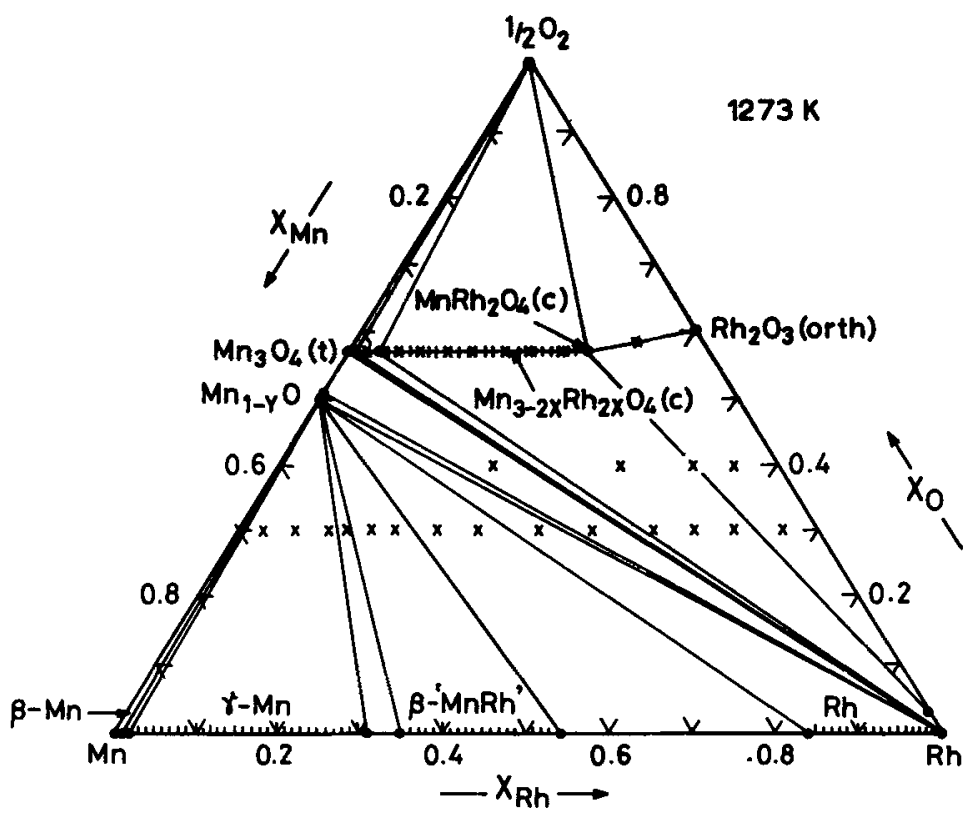

Figure 5. Phase relations in the system Mn-Rh-O at $1273 \mathrm{~K}$. The compositions of the samples analyzed are shown by $\times$ (after Jacob and Sriram 1994).

The potential readings were corrected for small thermal emfs, measured separately.

As the cell potential of the three-electrode assembly is determined only by the chemical potentials of oxygen in the measuring and reference electrodes, the effective cell can be concisely written as:

$$
\mathrm{Pt}-\mathrm{Rh}, \mathrm{Rh}+\mathrm{Mn}_{3-2 X} \mathrm{Rh}_{2 X} \mathrm{O}_{4}\left\|\left(\mathrm{Y}_{2} \mathrm{O}_{3}\right) \mathrm{ZrO}_{2}\right\| \mathrm{O}_{2}\left(1.01 \times 10^{5} \mathrm{~Pa}\right), \mathrm{Pt}-\mathrm{Rh} .
$$

The cell is written such that the right-hand electrode is positive.

Chemically invariant two-phase mixtures at constant temperature and pressure in binary systems were also measured using 'three-compartment design' of the cell. Studies were conducted on cells:

$$
\mathrm{Pt}-\mathrm{Rh}, \mathrm{Rh}+\mathrm{Rh}_{2} \mathrm{O}_{3}\left\|\left(\mathrm{Y}_{2} \mathrm{O}_{3}\right) \mathrm{ZrO}_{2}\right\| \mathrm{O}_{2}\left(1.01 \times 10^{5} \mathrm{~Pa}\right), \mathrm{Pt}-\mathrm{Rh}
$$

and

$$
\text { Pt, } \mathrm{Mn}_{1-Y} \mathrm{O}+\mathrm{Mn}_{3} \mathrm{O}_{4}\left\|\left(\mathrm{Y}_{2} \mathrm{O}_{3}\right) \mathrm{ZrO}_{2}\right\| \mathrm{O}_{2}\left(1.01 \times 10^{5} \mathrm{~Pa}\right), \mathrm{Pt}
$$

The measuring and buffer electrodes in these cells had identical composition.

\subsection{Results and discussion}

The reversible emf of cell (1) is shown as a function of temperature in figure 6 for different compositions of the oxide solid solution. The reversibility of the emf 


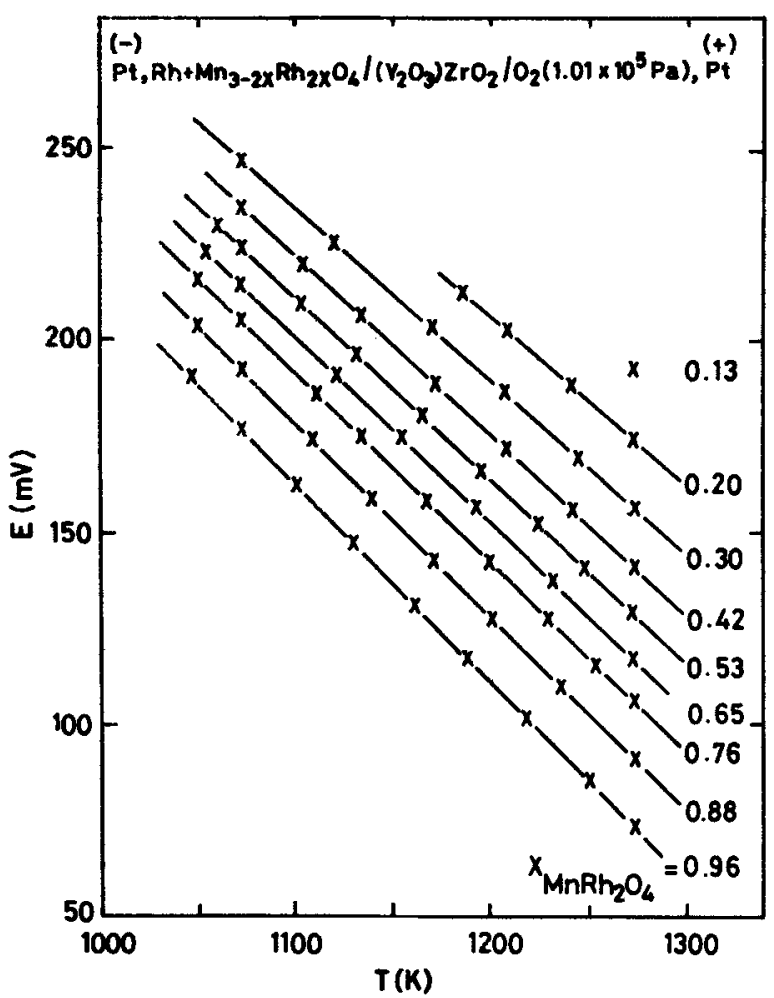

Figure 6. Tempernture dependence of the emf of cell (1) for different compositions of the solid solution.

was checked by microcoulometric titration in both directions. A small quantity of current $(\sim 50 \mu \mathrm{A}$ for $300 \mathrm{~s})$ was passed through the cell using an external potential source. The open circuit emf was then monitored as a function of time. After each such titration, the emf returned to the original value before titration, thus ensuring cell reversibility. The emf was not affected by the flow rate of oxygen through the reference electrode in the range $2-5 \mathrm{ml} \mathrm{s}^{-1}$.

With the 'three-electrode design' of the cell, the emfs were steady $( \pm 0.3 \mathrm{mV})$ for periods in excess of $30 \mathrm{ks}$. The buffer electrode contained a solid solution with the next lower concentration of $\mathrm{MnRh}_{2} \mathrm{O}_{4}$ than the measuring electrode. The emf of the buffer electrode against the reference was higher by $10-18 \mathrm{mV}$ than that of the measuring electrode at the start of each experiment. As a consequence of the flux of oxygen from the reference electrode, the emf of the buffer-electrode gradually decreased to a value $\sim 15 \mathrm{mV}$ lower than that of the measuring electrode by the end of the experiment. This clearly demonstrates the need for the buffer to absorb the oxygen flux and protect the measuring electrode from being disturbed. The emf between the buffer and measuring electrodes is a direct measure of polarization.

Studies on cells (3) and (4) indicate that the difference between the emf of the buffer and the measuring electrode increases from a value of zero at the beginning of the experiment to a maximum value of $\sim 3.5 \mathrm{mV}$ at the end. Thus the semipermeability 
flux of oxygen from the oxygen reference through the solid electrolyte does not appear to significantly change the chemical potential of systems that are invariant under the experimental conditions. Nevertheless, use of a buffer is recommended for very precise measurements of invariant equilibria in the future, especially when the driving force for oxygen transport is large. Such situations are encountered when pure oxygen or air is used as a reference electrode and measurements are made on systems with low oxygen chemical potential.

\section{Design of a galvanic cell with four compartments}

\subsection{Principle}

The 'three-compartment cell' design does not completely solve the polarization problem unless one of the electrodes is nonpolarizable. When the reference electrode is also polarizable, two buffer electrodes are required between the reference and measuring electrodes. To protect the reference electrode from polarization, a reference-buffer electrode, identical to the reference electrode is interposed. Thus, in the absence of a driving force, there is no transport of the active species between the reference-buffer and reference electrodes. Similarly, the measuring electrode is also insulated using a buffer of approximately same chemical potential. The chemical potential difference exists between the two buffers, which may become polarized due to coupled transport of ions and electronic charge carriers through the electrolyte separating them. During the course of experiment, the oxygen chemical potential of the buffer electrodes may thus change from their initial values. The cell emf, which is related to the oxygen chemical potential difference between the measuring and the reference electrodes, is unaffected.

The use of a four-compartment cell design permits more accurate thermodynamic measurements on metal and ceramic systems at high temperature. A four-compartment galvanic cell was used for accurate thermodynamic measurements on $\mathrm{LaRhO}_{3}$ at high temperature (Jacob and Waseda 1995). The cell consisted of four distinct compartments, separated by yttria-stabilized zirconia tubes and crucibles. The cell, schematically depicted in figure 7 , can be represented as:

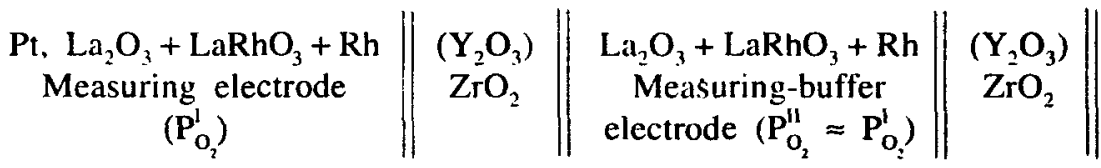

$$
\begin{aligned}
& \left\|\begin{array}{c||c||c}
\mathrm{Rh}+\mathrm{Rh}_{2} \mathrm{O}_{3} \\
\text { Reference-buffer } \\
\text { electrode }\left(\mathrm{P}_{\mathrm{O}_{2}}^{\mathrm{III}} \approx \mathrm{P}_{\mathrm{O}_{2}}^{\mathrm{IV}}\right)
\end{array}\right\|\left(\begin{array}{c}
\left.\mathrm{Y}_{2} \mathrm{O}_{3}\right) \\
\mathrm{ZrO}_{2}
\end{array} \| \begin{array}{c}
\mathrm{Rh}+\mathrm{Rh}_{2} \mathrm{O}_{3}, \mathrm{Pt} \\
\text { Reference electrode } \\
\left(\mathrm{P}_{\mathrm{O}_{2}}^{\mathrm{IV}}\right)
\end{array}\right.
\end{aligned}
$$

The reference electrode was prepared by compacting an intimate mixture of $\mathrm{Rh}$ and $\mathrm{Rh}_{2} \mathrm{O}_{3}$ in the molar ratio $\mathrm{I}: 1.5$ against the closed end of yttria-stabilized zirconia tube, with a $\mathrm{Pt}-30 \% \mathrm{Rh}$ lead embedded in the mixture. The reference-buffer electrode was prepared in an identical tashion using a stabilized-zirconia tube of 


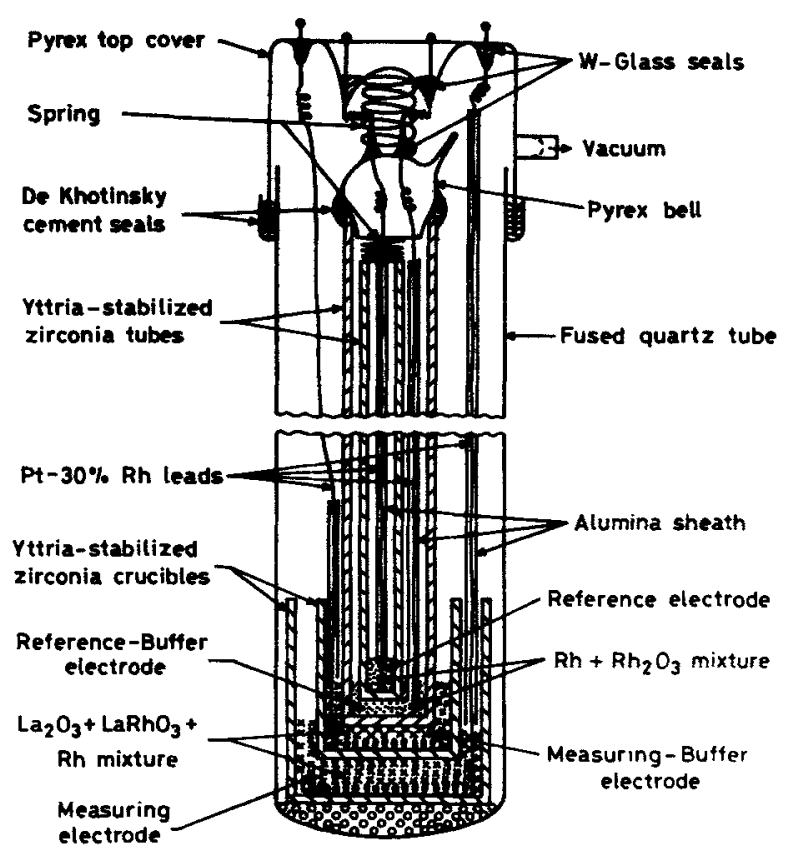

Figure 7. A schematic representation of the four-compartment cell arrangement for emf measurement.

larger diameter. The smaller zirconia tube containing the reference electrode was placed inside the larger tube.

The measuring electrode was prepared by compacting a mixture of $\mathrm{La}_{2} \mathrm{O}_{3}, \mathrm{LaRhO}_{3}$ and $\mathrm{Rh}$ in the molar ratio $1: 1.5: 1$ in a stabilized-zirconia crucible, with a Pt-30\% $\mathrm{Rh}$ lead buried in it. The measuring-buffer electrode was prepared in the same way inside a crucible with smaller diameter. The larger zirconia tube containing the reference-buffer electrode was placed over the measuring-buffer electrode in the smaller crucible, and the space between them was filled with the three-phase electrode mixture. The compartments were assembled as indicated in figure 7 , following a procedure similar to that described in the earlier section.

As the cell potential of the four-electrode assembly is determined only by the chemical potentials of oxygen in the measuring and reference electrodes, the effective cell can be concisely written as:

$$
\mathrm{Pt}, \mathrm{La}_{2} \mathrm{O}_{3}+\mathrm{LaRhO}_{3}+\mathrm{Rh}\left\|\left(\mathrm{Y}_{2} \mathrm{O}_{3}\right) \mathrm{ZrO}_{2}\right\| \mathrm{Rh}+\mathrm{Rh}_{2} \mathrm{O}_{3} \text {, Pt. }
$$

Again, the cell is written such that the right-hand electrode is positive.

\subsection{Results and discussion}

The reversibility of the emf of cell (5) was established by microcoulometric titration in both directions. The emf measured between the two buffer electrodes was always 


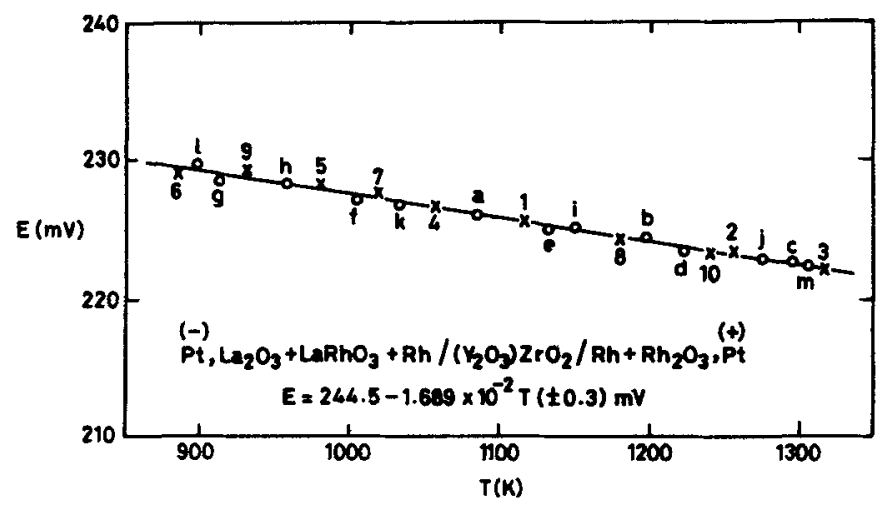

Figure 8. Temperature dependence of the emf of cell (5).

lower by 2 to $3.5 \mathrm{mV}$ than that between the measuring and reference electrodes. When microcoulometric titration was done between the buffer electrodes, there was a small hysteresis effect of $\sim 2 \mathrm{mV}$. This indicated a finite polarization effect due to the flux of oxygen from the reference-buffer to the measuring buffer electrode. Although both electrode systems are invariant at constant temperature, measurement of their oxygen potential using the conventional solid state cell can result in a small but significant systematic error. The use of the four-compartment design improves the accuracy by insulating the measuring and reference electrodes from polarization effects.

The reversible emf of cell (5) is shown in figure 8 as a function of temperature. Emf was found to be reproducible on temperature cycling. The standard Gibbs free energy change for the overall cell reaction:

$$
\begin{aligned}
& \mathrm{Rh}_{2} \mathrm{O}_{3}+\mathrm{La}_{2} \mathrm{O}_{3} \rightarrow 2 \mathrm{LaRhO}_{3}, \\
& \Delta G_{7}^{\circ}=-141,560+9.78 T( \pm 180) \mathrm{J} \mathrm{mol}^{-1},
\end{aligned}
$$

is obtained directly from the emf. There are no data in the literature with which these values can be compared.

\section{Summary}

The application of buffer electrodes is investigated for minimizing electrode polarization in high temperature solid state galvanic cells. In the absence of physical porosity, the polarization is caused by the electrochemical permeability, which results from the coupled transport of the mobile species and electronic charge carriers in the solid electrolyte under a chemical potential gradient. When a nonpolarizable reference electrode is employed, a cell with three-electrode compartments can be used to insulate the measuring electrode from electrode polarization. The buffer electrode, introduced between the reference and the measuring electrodes, acts as a sink for the electrochemical flux and prevents it from reaching 
the measuring electrode. The polarization problem is not completely solved in a three-compartment cell design unless one of the electrodes is nonpolarizable. Two buffer electrodes are required between the reference and measuring electrodes when both the electrodes are susceptible to polarization effects. In a four-compartment cell design, accuracy of measurement is improved by insulating both the electrodes using buffers. The use of a buffer permits precise thermodynamic measurements on metal and ceramic systems at high temperature, especially for systems with one or more degrees of freedom at constant temperature.

\section{References}

Charette G G and Flengas S N 1968 J. Electrochem. Soc. 115796

Fouletier J, Fabry P and Kleitz M $1976 J$. Electrochem. Soc. 123204

Jacob K T, Iwase $M$ and Waseda $Y 1982 J$. Appl. Electrochem. 1255

Jacob K T and Jeffes J H E 197 ! Trans. Inst. Min. Mefall. C80 C181

Jacob K T and Mathews T 1990 Indian J. Tech. 28413

Jacob K T and Sriram M V 1994 Metall. Trans. A25 1347

Jacob K T and Waseda Y $1995 \mathrm{~J}$. Am. Ceram. Soc. 78 (in press)

Lundberg $M$ and Rosén E $1992 \mathrm{~J}$. Am. Ceram. Soc. 751452

Kale G $M$ and Jacob K T 1992 Metall. Trans. B23 57

Mallika C, Pankajavalli R and Sreedharan O M 1986 Electrochim. Acta 31885

Pratt J N 1990 Metall. Trans. A21 1223 